\title{
¡PONTE EN MIS ZAPATOS!
}

\section{$7 \mathrm{POLI}$}

\author{
Put yourself in my shoes!
}

Camila Andrea Sánchez Guasca

casanchez32@poligran.edu.co

\author{
Politécnico Grancolombiano \\ Diseño Gráfico \\ Colombia
}

\begin{abstract}
RESUMEN
Reconocer la violencia psicológica según la definición del Sistema Integral de Violencias de Género (SIVIGE), como todo acto u omisión destinado a humillar y dominar las acciones, conductas, pensamientos y determinaciones de otras personas. Colombia es un país en donde los índices de violencia de género e intrafamiliar son altos, se debe concientizar sobre esta situación mediante un objeto como el calzado. Se desea hacer un análisis de esta situación.
\end{abstract}

Ponte en mis zapatos nace de una anécdota sobre violencia intrafamiliar, se realizan unas ilustraciones que acompañan el texto para dar relevancia a la cultura colombiana; la investigación inicial se aborda desde el significado del calzado junto con la violencia de género y violencia intrafamiliar. Según datos analizados en la página de la Fiscalía, se encuentra que la violencia psicológica no posee grandes estudios.

Las mujeres son las más vulneradas en términos de violencia; según el SIVIGE, esta entidad hace un análisis que muestra que a mediados del 25 de marzo y el 21 de abril de 2021 se han incrementado los casos de violencia de género debido a la pandemia. La Fiscalía nos muestra un estudio en donde el $64,1 \%$ de la población femenina manifiesta ser violentada psicológicamente, pero solo un 10\% denuncia.

Según información contenida en el Boletín de estudios de violencia de la Fiscalía, Colombia no posee los suficientes datos sobre violencia psicológica, ya que este tipo de actitudes en las familias se normalizan. Por tal razón, se evidencia una necesidad de educar a la población sobre el factor emocional para expresar y buscar apoyo en este tipo de situaciones. Este proyecto empezó en junio del presente año y continúa en curso, contrastando la información de proyectos similares de otros países.

\section{PALABRAS CLAVE:}

Zapatos, calzado, género, feminismo, violencia

Cite este artículo como: Sánchez, C. (2021). „Ponte en mis zapatos!

\section{INTRODUCCIÓN}

Este manuscrito pretende entregar los resultados a la siguiente pregunta: ¿Cuáles son los orígenes de una sociedad que expone un gran número de casos de violencia contra la mujer, donde sus agresores son en la mayoría los mismos familiares y cómo afecta esto el rol de la mujer actualmente en la sociedad colombiana?, donde se realiza una mirada sobre un objeto de uso cotidiano, como lo es el zapato, y los estudios de violencia. Para ello se han encontrado textos como La historia del zapato, que nos muestra cómo la salud de los pies no es 
un problema que se trate (Montes, 2007 ); La esencia del estilo de las botas del rey, nos relata cómo los zapatos con tacón fueron usados por los hombre de élite y cómo llegaron a la industrialización (Dejean, 2005; DazaOrozco, 2014); y Revisión sobre la evolución del zapato de tacón según un contexto histórico y su efecto en la salud de sus usuarios (Valderrama, Castaño \& Velásquez, 2016). Por el lado de la investigación sobre violencia se buscan blogs especializados y estudios como Violencia intrafamiliar contra niñas y adolescentes mujeres en Colombia (2009-2004), Violencia contra la mujer en el marco de las relaciones de pareja en Colombia (2009-2014), y un último boletín sobre la violencia a las mujeres en épocas de pandemia, donde se muestran análisis sobre los factores comunes que presentan las víctimas y estadísticas de hechos de violencia. Por último, en cuanto a material audiovisual está el documental Las tres muertes, de Marisela Escobedo.

Al encontrar todos los días casos de feminicidios, historias cercanas sobre mujeres violentadas y la violencia que se ejerce en los hogares, se crea un lazo emocional sobre el proyecto donde se muestra lo que sucede tradicionalmente en los hogares colombianos y las causas que generan feminicidios o infanticidios. Es necesario que la sociedad colombiana reflexione sobre la normalización de la violencia en los hogares y diferencie cuándo se ejerce violencia psicológica a una persona, ya que la mayoría de las víctimas no lo saben. En muchos de los casos de feminicidios, son las prendas de vestir la única evidencia que se encuentra, es por eso que en este proyecto se enfatiza en calzado como un objeto que ha representado la evolución del hombre.

Al realizar el curso "Escribiendo un Nueva Historia IDPAC", se encuentra el término de la violencia simbólica, como la violencia normalizada por estereotipos, ideales, religión y normas contra la mujer (García, 2017). Este nuevo término le aporta al proceso de investigación una forma de abordar la significación y la simbología como tema principal para desarrollar la metáfora del zapato.

La investigación se encuentra limitada en cuanto a estudios actualizados sobre la violencia de género y violencia intrafamiliar, por tal razón, se busca apoyo desde el área de psicología para examinar y recolectar historias para entender cuál es el factor común de estos casos de violencia que se han incrementado debido a la pandemia. 


\section{METODOLOGÍA}

A través de un texto de la clase de ilustración sobre

violencia intrafamiliar, se usa el calzado como metáfora

del sufrimiento de la persona agredida

Se utiliza un método epistemológico,

donde se hace una recolección de datos

históricos, estadísticas, definiciones y

sentencias actuales sobre la protección de

la mujer.

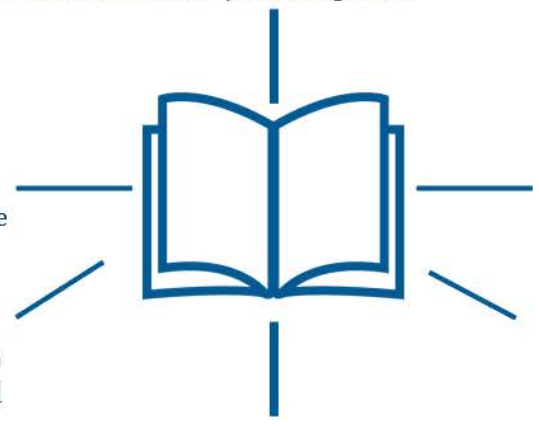

Búsqueda de literatura, documentales, imágenes y blogs.

Revisión de trabajos y exposiciones de artistas plásticos que tengan como tema central el calzado.

Consulta de información para la investigación desde la biblioteca virtual del Politécnico Grancolombiano.

\footnotetext{
Se reúnen referencias y aproximaciones investigativas de estudios realizados por el gobierno.

Violencia simbólica
}

MÉTODO

Textos de la investigación

\begin{tabular}{|c|c|c|}
\hline Lugar de búsqueda & Tipo de texto & Nombre y autor \\
\hline $\begin{array}{l}\text { Base de datos de la biblioteca del } \\
\text { Politécnico }\end{array}$ & Texto universitario, prosa. & $\begin{array}{c}\text { Descripción de un sentimiento, Paula Nathalia } \\
\text { Pineda Ortiz. }\end{array}$ \\
\hline Web & Pdf-Artículo & $\begin{array}{c}\text { La historia del zapato, María de la Luz Montes } \\
\text { Castillo. }\end{array}$ \\
\hline Libro & Pdf-libro escaneado-fragmento & $\begin{array}{l}\text { La esencia del estilo de las botas del rey, Joan } \\
\text { de Jean (Capitulo IV) }\end{array}$ \\
\hline Web-Plataforma & Pdf- Artículo & $\begin{array}{l}\text { Revisión sobre la evolución del zapato de tacón } \\
\text { según su contexto histórico y su efecto en la } \\
\text { salud de sus usuarios, Sebastián Valderrama, } \\
\text { Patricia Cataño y Sandra Velázquez. }\end{array}$ \\
\hline Web Plataforma & Pdf- Artículo & $\begin{array}{l}\text { Zapatos: andantes con variaciones, Margo } \\
\text { Glantz }\end{array}$ \\
\hline Sitio Web & Blog & Tipos de violencia, significados.com \\
\hline Fiscalía General de la Nación & Estudios sobre violencia & $\begin{array}{l}\text { Violencia intrafamiliar contra niñas y } \\
\text { adolescentes mujeres en Colombia,2009-2014, } \\
\text { Damaris Constanza Heredia Melo. }\end{array}$ \\
\hline Fiscalía General de la Nación & Estudios sobre violencia & $\begin{array}{l}\text { Violencia contra la mujer en el marco de las } \\
\text { relaciones de pareja en Colombia, 2009-2014, } \\
\text { Martha Elena Pataquiva Wilches. }\end{array}$ \\
\hline Fiscalía General de la Nación & Estudios de violencia- Boletín & $\begin{array}{c}\text { Boletín de respuesta institucional para el } \\
\text { abordaje integral de las violencias por razones } \\
\text { de género (contra niñas, niños, adolescentes y } \\
\text { mujeres), durante el aislamiento preventivo } \\
\text { obligatorio, } 25 \text { de marzo al } 21 \text { de abril. }\end{array}$ \\
\hline Fiscalía General de la Nación & Estudios violencia & Violencia de la mujer Enero y febrero 2019 \\
\hline Netflix & Material audiovisual & Las tres muertes de Marisela Escobedo. \\
\hline Escribiendo una Nueva Historia IDPAC & $\begin{array}{l}\text { Certificación, prevención de violencia } \\
\text { intrafamiliar y de género. Artículo. }\end{array}$ & $\begin{array}{l}\text { ¿Qué es la violencia simbólica?, María Eugenia } \\
\text { García. }\end{array}$ \\
\hline
\end{tabular}


Tabla 1 Textos de la investigación. Textos organizados cronológicamente.

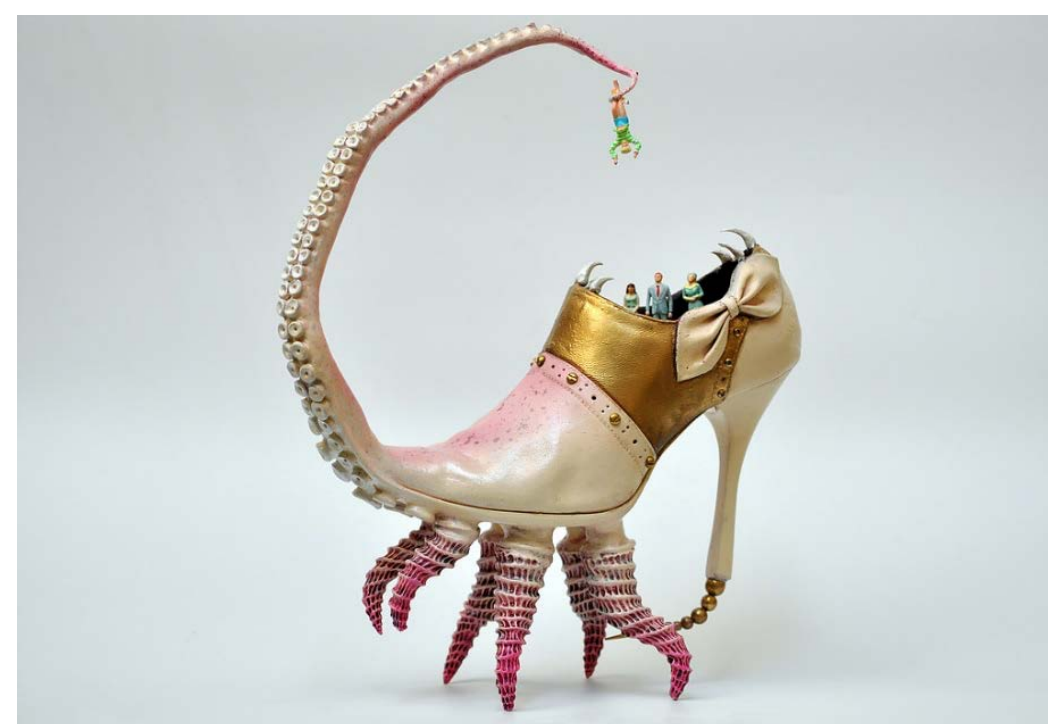

Imagen 1. Arte plástico de Costa Magarakis, referencia visual. https://cutt.ly/kgUdKSO

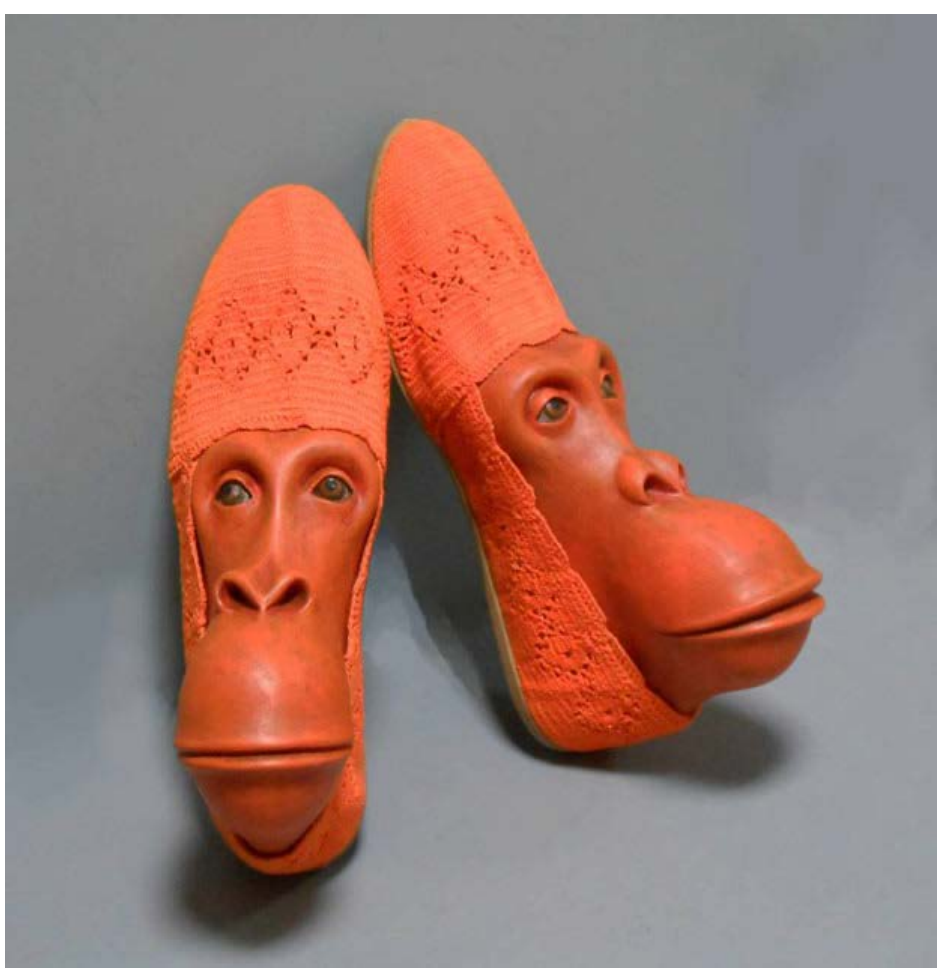

Imagen 2. Arte plástico de Gwen Murphy, referencia visual. https://cutt.ly/OgUfBrv 


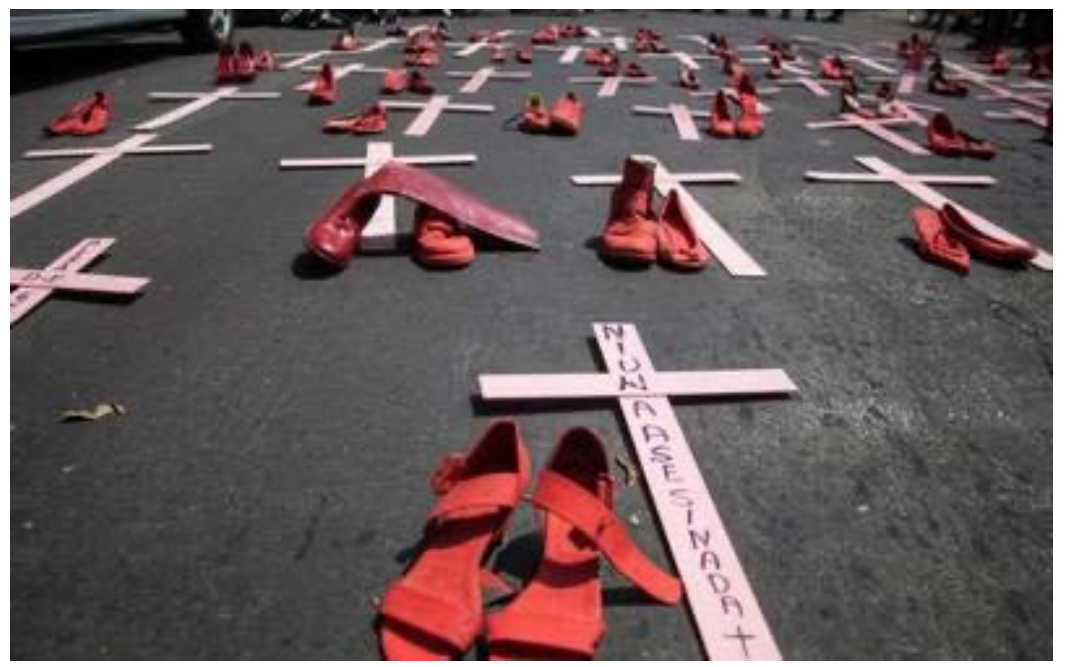

Imagen 3. Hidalgo registra 59 asesinatos violentos de mujeres en 2019. https://cutt.ly/DgUdhWc

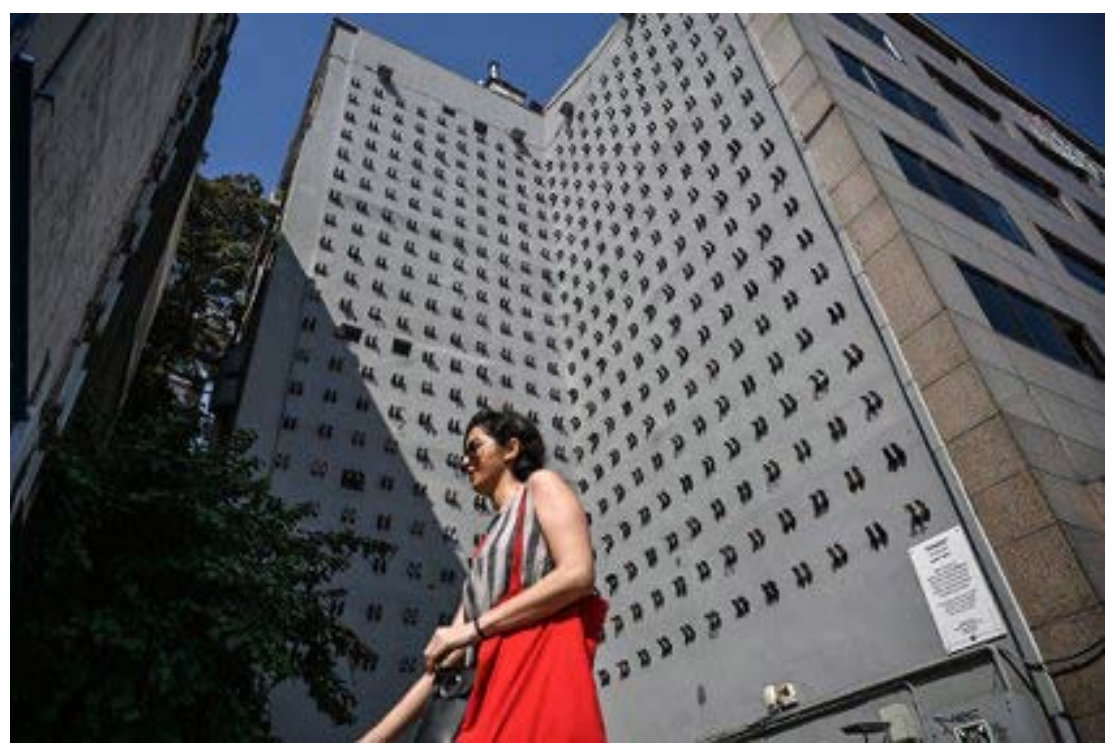

Imagen 4. 440 zapatos en un edificio mostrando las mujeres asesinadas por sus maridos. https://cutt.ly/kgUdKS0 


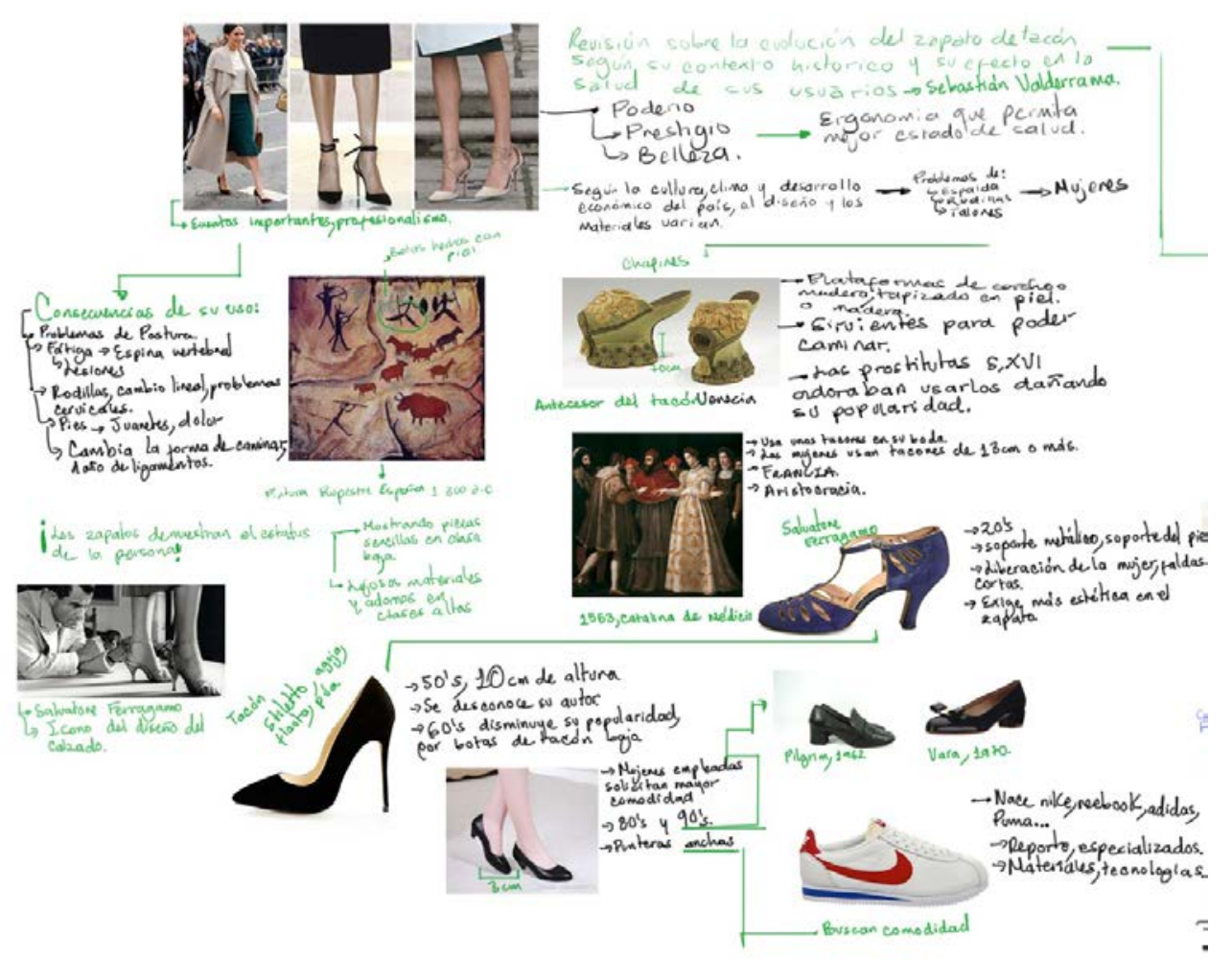

Imagen 5. Mapa mental sobre textos investigados del calzado.

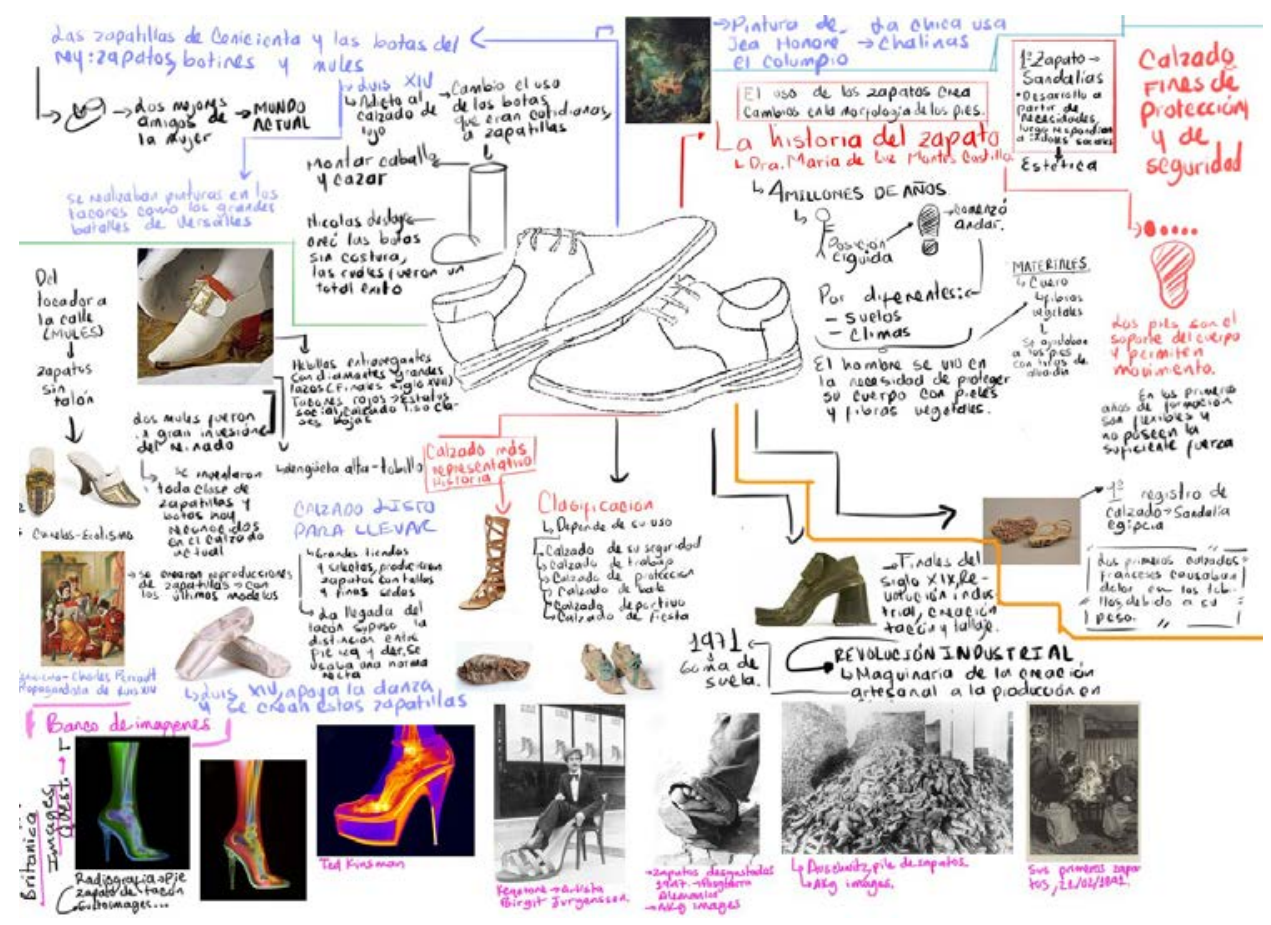

Imagen 6. Mapa mental sobre textos investigados del calzado. 


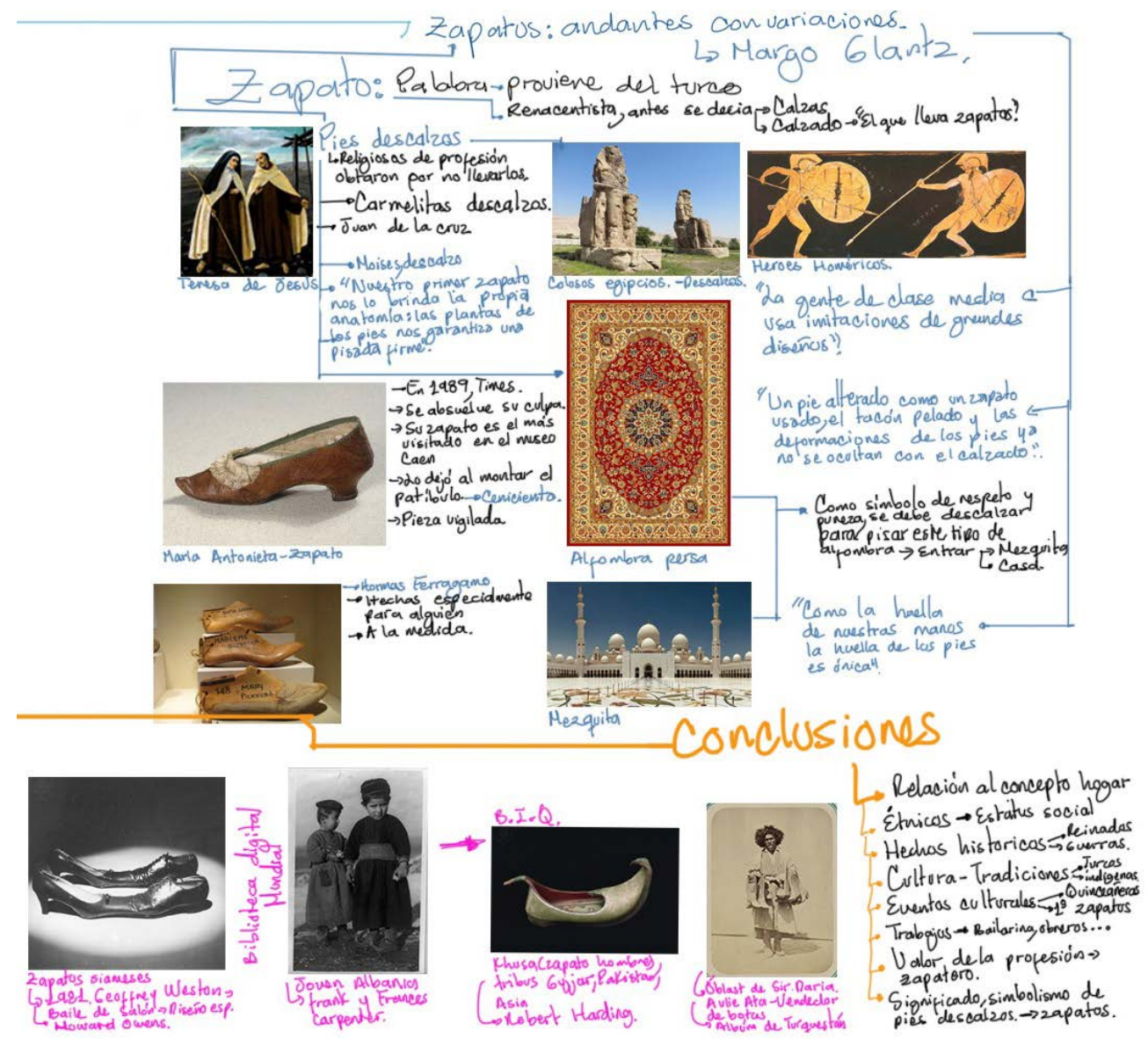

Imagen 7. Mapa mental sobre textos investigados del calzado.

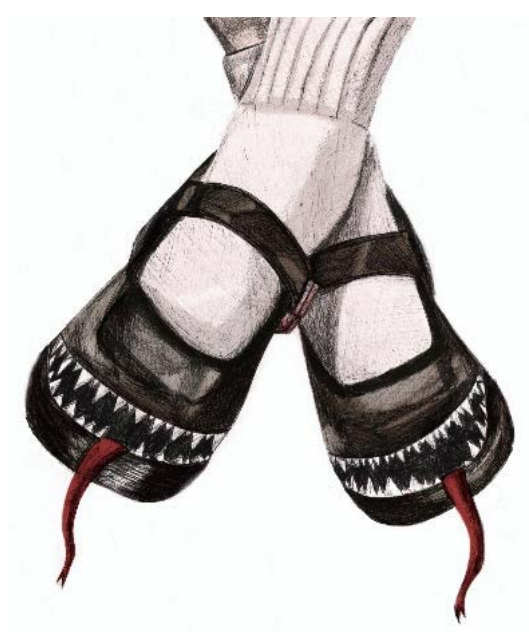

Imagen 8. Ilustración desarrollada sobre el texto Descripción de un sentimiento. 


\section{RESULTADOS}

El estudio determina que la relación entre el calzado y la violencia de género y violencia intrafamiliar está fuertemente ligada en términos de estética e historia, las alteraciones de la imagen de una persona pueden determinar la vida que lleva, se relaciona el concepto hogar en el calzado y violencia, como acercamiento de ser el lugar de inseguridad para muchas mujeres. Se encuentra una relación cultural entre la violencia y el calzado en cuanto las dos muestran un factor de tradiciones y comodidad por parte de la sociedad. Un gran porcentaje de las mujeres colombianas se han sentido agredidas en alguna etapa de su vida, donde los registros de violencia psicológica muestra ser la más usada (Pataquiva, 2009-2014), pero es la menos denunciada, se puede ver que el país no tiene un buen acompañamiento para la salud mental, por lo tanto, existen muchos desequilibrios emocionales en los colombianos.

Las niñas y mujeres son las más violentadas; se observa que los lugares donde más se encuentran víctimas son las zonas rurales, por falta de información y acceso a centros de ayuda. Por otro lado, se observa que la violencia termina siendo un gran problema para la sociedad colombiana y se concluye a través de la investigación que es un problema de salud pública (Heredia, 2009-20014).

Al observar los bancos de imágenes, se encuentran resultados históricos sobre zapatos en la Segunda Guerra Mundial, como muestra de lo que se vivió en esta época; algunos artistas han enfrentado esta situación sociopolítica con este objeto. El calzado como metáfora de la violencia posee una interesante conexión, ya que en nuestro país podemos relacionarlo con diferentes tipos de comunidades, tradiciones e historias; es por lo mismo que la modificación de este objeto para representar la violencia puede causar un gran impacto en las personas, pues es un objeto de la vida cotidiana.

\section{DISCUSIÓN Y CONCLUSIÓN}

Los estudios y la apropiación de un tema como la violencia de género e intrafamiliar no se expone para la mayoría del público. Es necesario entender qué es la violencia psicológica y como está conectada a través de un objeto, qué sucede en nuestra sociedad y cuál es el verdadero problema de los casos de violencia; tanto las mujeres como los hombres deben ser conscientes de si viven algún tipo de violencia, y considerar la salud mental como algo esencial para la estabilidad emocional.

Se habla de unos antecedentes políticos y culturales de la sociedad colombiana que afectan gravemente las relaciones interpersonales de los colombianos, sin olvidar que es una sociedad donde diariamente se viven casos de feminicidio, gracias al modelo mental tradicional del poder patriarcal (Minsalud).

Para ello se requiere hacer una mirada histórica sobre Colombia y el núcleo familiar, cómo se ha visto afectado a través de los años por la religión y las costumbres aprendidas, la educación y la postura de la mujer en nuestra sociedad. Por otro lado, el calzado como instrumento de la evolución de la historia colombiana es un tema que se debe abordar, el inicio de su industrialización y el poder que representaba, cómo la mujer empezó a tener como elemento principal este objeto a la hora de demostrar su posición en la sociedad. La violencia en Colombia ha tenido varias prendas de vestir muy significativas, entre ellas el zapato, conocer las historias y la simbología que representa cierto tipo de calzado es una investigación que permite que observemos nuestra cultura.

\section{REFERENCIAS BIBLIOGRÁFICAS}

Boletín Estadístico Mensual. (2020). Instituto Nacional de Medicina Legal y Ciencias Forenses. Enero. Colombia.

Daza-Orozco, C. (2018). Escritura con estilo: Guía práctica para publicar científicamente. Colombia: Fundación Universitaria San Mateo.

Daza-Orozco, CE. (2014). La alienación viste a la moda: análisis fílmico desde la tipificación ideal weberiana. El ojo que piensa - Revista de cine iberoamericano, 1(9). https://doi.org/10.13140/RG.2.2.21231.66726 
Dejean- Joan. (2015). La esencia del estilo Las botas del rey. Capítulo IV. La zapatilla de Cenicienta y las botas del rey: zapatos, botines y mules.

Glantz, M. (s.f.). Zapatos: andante con variaciones. Edición digital a partir de Narrativa, presentación de Beatriz Aguad, México.

Gobierno de Colombia, UNFPA, Las mujeres cuentan, ONU Mujeres. (2020). Boletín de respuesta institucional para el abordaje integral de las violencias por razones de género (contra niñas, niños, adolescentes y mujeres) durante el aislamiento preventivo obligatorio 25 de marzo al 21 de abril.

Heredia, D. (2009- 2014). Masatungo niñas. Violencia intrafamiliar contra niñas y adolescentes mujeres en Colombia, 2009-2014. Colombia.

Montes, M. (2007). El uso del calzado: ¿cuándo, por qué? y sus consecuencias. Revista Mexicana de Medicina Física y Rehabilitación.

Pataquiva, M. (2009-2014). Violencia contra la mujer en el marco de las relaciones de pareja en Colombia, 20092014. Colombia.

Silva, P. (2018). La violencia intrafamiliar: maltrato a la mujer y a los hijos. Recuperado de: https://www.psicologiaonline.com/la-violencia-intrafamiliar-maltrato-a-la-mujer-y-a-los-hijos-2031.html.

Valderrama, S., Castaño, P., \& Velásquez, S. (2016). Revisión sobre la evolución del zapato de tacón según su contexto histórico y su efecto en la salud de sus usuarios. Colombia. 